\title{
Sustainable and Resilient Smart Water Grids: A Solution for Developing Countries
}

\author{
Muhammad Jawwad' ${ }^{1}$ Khurram S. Khattak' ${ }^{1}$ Zawar H. Khan'2, \\ T. Aaron Gulliver ${ }^{2}$, Akhtar N. Khan ${ }^{1}$ and Mushtaq A. Khan ${ }^{3}$ \\ ${ }^{1}$ National Center for Big Data \& Cloud Computing, UET Peshawar. \\ 2University of Victoria, Canada. \\ 3University of Engineering and Technology Mardan, Mardan \\ Email: muhammadjawwad@outlook.com,khurram.s.khattak@gmail.com*, \\ khanuvic@gmail.com, agullive@ece.uvic.ca, engrakhtarkhan@gmail.com, \\ mushtaq@uetmardan.edu.pk
}

Received April 8, 2021; Revised May 11, 2021; Accepted June 15, 2021

\begin{abstract}
According to a United Nations report, the world population will increase from 7 billion to 9 billion by 2050. Further, the water stress level is more than $70 \%$ in 22 countries while in another 31 countries it is between $25 \%$ and $70 \%$. More than 2 billion people live in these 53 countries which are all underdeveloped. Water use has increased by $1 \%$ per year since the 1980 s, so global demand is expected to rise by $30 \%$ by 2050 . Thus, efficient water grid management is imperative to ensure there is sufficient water for the future. Information and Communication Technology (ICT) can be used to create smart water grids to optimize water distribution, reduce waste and leakage, and resolve quality and overuse issues. In this work, a low cost, real-time, reliable and sustainable IoT based solution called SmartTubewell is proposed for smart water grid management. It is composed of two components, a sensor node installed at tube wells and an application layer on Amazon Web Services (AWS) for data analysis, storage and processing. The sensor node is based on a Raspberry Pi with integrated current and voltage sensors and a local database. The sensor data is transmitted to AWS using a cellular (GPRS) network. A comparison between the proposed system and SCADA is presented which shows that SmartTubewell has a much lower cost. A field test with multiple tube wells in Peshawar, Pakistan indicates that this is a suitable solution for developing countries.
\end{abstract}

Keyword: Smart water grid, Internet of Things (IoT), tube well, Amazon Web Services (AWS)

\section{INTRODUCTION}

Water is an essential resource for human life. The current water shortfall faced by a major part of the world's population has led to concerns about survival in many regions. Only $0.01 \%$ of the $3 \%$ fresh water on earth is clean and human consumable [1]. Increasing population, industrialization 
and urbanization is rapidly reducing this small proportion of potable water. According to the World Health Organization (WHO), 30\% of hospital admissions are due to water-related diseases and these account for $60 \%$ of infant deaths [2]. This problem is even more serious in developing countries in general and South Asia in particular. South Asia includes India, Pakistan, Bangladesh, Sri Lanka and Bhutan and has a population of approximately 2 billion people. These countries have similar weather and water resource conditions. The underground water reservoirs are the primary source of water for domestic, irrigation and industrial use. This water supply will be exhausted if steps are not taken to preserve and optimize this precious resource. Smart Water Grid (SWG) solutions based on the Internet of Things (IoT) paradigm can play a key role in solving this challenge.

SWGs are water infrastructure management systems that can collect and share real-time water infrastructure data through interconnected embedded devices. Some of these devices can take physical actions based on information received from sensors. SWGs provide control and efficiency to urban water management. These efficiencies include limiting water waste, losses, leakages, theft and Non-Revenue Water (NRW). IoT based SWGs can increase the efficiency, robustness, sustainability and availability of Water Distribution Networks (WDNs). The IoT provides a central hub to pool data from humans as well as sensor nodes using the internet as a communication medium. It can be used to provide a variety of services to people as well as public and private organizations. IoT solutions have been proposed for application in industrial automation, health care, energy and traffic management [3-7].

In this paper, a low cost, reliable and efficient IoT based system called SmartTubewell is proposed for SWG systems. The sensor nodes are based on a Raspberry Pi for automation and control of three-phase submersible water pumps installed at each tube well station. Current and voltage sensors are integrated for real-time monitoring of tube wells with a local database for logging purposes. An Amazon Web Service (AWS) based web interface and back-end database is employed for control, scheduling, monitoring and management of tube well stations. Data from sensor nodes is transmitted to AWS servers using cellular (GPRS) communications.

The rest of this paper is organized as follows. Section II provides the background and discusses the importance of SWGs. Section III details the proposed novel solution while Section IV presents the SmartTubewell system design. Experimental results and an analysis of the proposed solution are given in Section V. Finally, some concluding remarks are presented in Section VI.

\section{RELATED WORKS}

In developed countries, water distribution systems provide running water to consumers. Each consumer is charged on a usage basis with higher prices above a threshold. This type of billing system encourages water 
conservation. Further, WDNs are well maintained and issues such as water losses, leakages and pipe breakages are dealt with in a timely and efficient manner. In developing countries, water distribution is typically based on a fixed cost over time. In South Asia in general and Pakistan in particular, the major source of potable water is underground water reservoirs. Water infrastructure is comprised of tube well stations with powerful submersible water pumps to extract underground water. Normally, water is pumped twice a day at predefined times for a fixed duration. Consumers have underground tanks for water storage and pumps to deliver water to overhead tanks for household consumption. This model of supplying water with unmetered usage and fixed billing results in inefficiencies and little motivation to conserve water.

The need for SWGs is motivated by the fact that South Asia is home to about 2 billion people. These people live mostly in water-stressed developing countries including Pakistan, India, Nepal, Sri Lanka, Bhutan, and Bangladesh [8]. In 2019, the water-stress level in these countries was above 70\% [8]. Thus, IoT based smart water management and distribution is imperative to overcome this challenge. To highlight water distribution inefficiencies in developing countries, Peshawar is considered as a case study in this work. Figure 1 shows that Peshawar, the provincial capital of Khyber Pakhtunkhwa (KPK) province, has a semi-arid climate. Peshawar has very hot summers (May to September) and mild winters (November to March). Rainfall in Peshawar occurs in both winter and summer. Based on 30 years of data, the average annual precipitation is $400 \mathrm{~mm}$ [9].

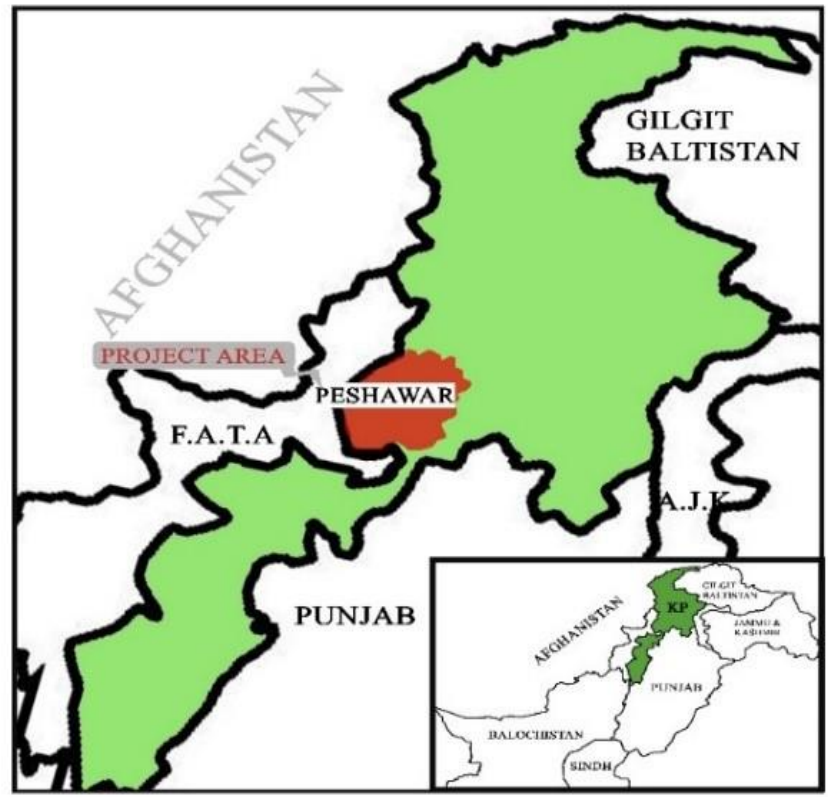

Figure 1. The location of Peshawar, Pakistan, which is the area for implementation of the proposed IoT based system. 


\section{Water Policies}

In developing countries, functions such as water distribution, drainage, sewage treatment and waterbody management are currently spread among various administrative departments in the metropolitan area. The subdivision of areas of operation in rural and urban areas within these departments further complicates water management. These divisions in conjunction with the lack of a centralized control center create ambiguity and confusion in rules, standards, approval, supervision, utilization and management of the water supply. Currently, there are no efforts to unify the laws and regulations related to the management of water systems. For example, Peshawar currently obtains potable water from approximately 1400 tube well stations [10]. Out of these, 506 are operated by the Water \& Sanitation Services Peshawar (WSSP), 53 by the Peshawar Development Authority (PDA), 23 by the Cantonment Board and the rest by various utilities and townships as shown in Figure 2.

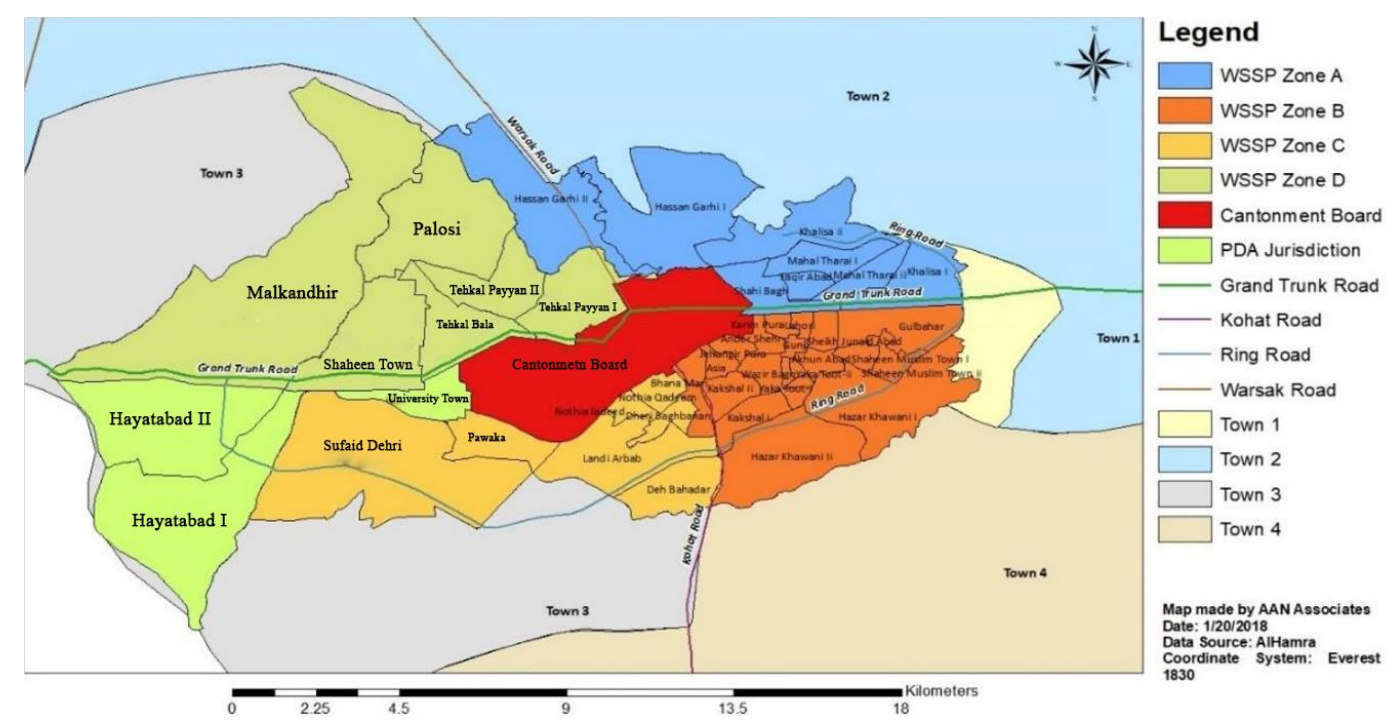

Figure 2. Peshawar city water supply agency areas of responsibility.

\section{Groundwater Management}

As the main source of water in developing countries, groundwater is a precious but limited resource that needs to be managed prudently. In the current management system, competing water utilities have installed tube wells without considering groundwater management. This has resulted in a drastic lowering of underground water table levels.

It is estimated that $1,200,000 \mathrm{~m}^{3}$ of water per day will be required for the Peshawar metropolitan area in 2032 [9]. To meet these demands, several aspects of underground water management must be taken into account. These include rate of water extraction, proper spacing between tube wells, falling water tables, and groundwater migration from higher recharge areas and low utilization areas towards high pumping areas. 


\section{Water Waste and Overuse}

The fixed cost over time water usage billing system in Pakistan is a major cause of water waste because there is no motivation for conservation. Hayatabad is a township located at the North-Western edge of Peshawar with a modern suburban area of 3299 acres. For administrative purposes, PDA has divided Hayatabad into seven areas. The population of Hayatabad is estimated at 100,000 living in 11250 households with an average of 8.5 people. The major source of potable water in Hayatabad is 53 tube wells with powerful submersible electric motors as shown in Figure 3. Each of these tube wells has an average water discharge capacity of $102-153 \mathrm{~m}^{3} / \mathrm{hour}$ operating 13 hours per day. Consumers are charged a flat fee of $\$ 38$ per month.

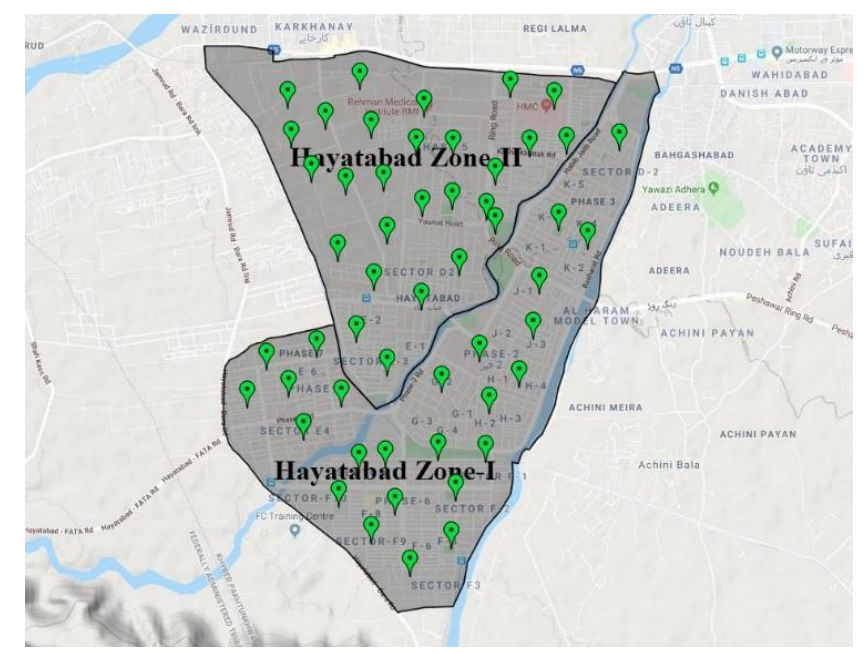

Figure 3. Hayatabad Township tube well locations.

\section{Non-Revenue Water (NRW)}

Non-Revenue Water (NRW) is water obtained using the operational cost of water extraction and distribution system but for which no revenue is generated. The reasons for NRW include unbilled water consumption, evaporation from open reservoirs, illegal connections to the water pipeline and inaccuracies in water measurement. In developing countries, one of the main reasons for water utility financial difficulties is high NRW levels. In South Asia, a lack of financing prevents new investments in water distribution infrastructure and this increases NRW levels. According to the World Bank, there were 45 million cubic meters of unaccounted water worldwide in 2016, resulting in a loss of $\$ 14$ billion [12]. Thus, it is important to mitigate these losses.

\section{Energy Consumption}

In a WDN, the major source of energy consumption is underground water extraction and maintaining constant pressure in the pipeline network using electric water pumps. According to the U.S. Environmental Protection 
Agency, on average $1.5 \mathrm{kWh}$ of energy is used to deliver, treat and distribute one thousand gallons of potable water in the U.S [13]. In South Asia, water is supplied from tube wells using submersible electric motors. Thus, energy consumption should be monitored at each source. Water is typically supplied two or three times per day to an area at fixed times and durations. This supply of water is not tracked until it reaches consumers, so little is known about WDN operations.

In Peshawar, approximately 1,400 tube wells supply groundwater to the public [10]. Over 50\% of these are more than 15 years old and only one has a functioning flow meter [9]. In addition to obsolete equipment which is inefficient, these tube wells are a major source of water and electricity theft. Leakage also increases the energy consumption per deliverable water unit.

\section{Smart Water Grids}

In this section, a cost analysis of the SWG management system is presented. Investment in new technology requires that the advantages outweigh the cost. The availability of a cost-effective, reliable and scalable IoT based SWG will motivate utilities to invest in this solution. In current water management systems, all tube wells are operated manually. Each tube well station has two operators, one for each of the morning and evening shifts. In an SWG management system, tube well supervisors have remote access to obtain event data logs, electricity consumption data and alarms, as well as allow for pump scheduling. Each supervisor is responsible for 10 tube wells and operators are not required. A tube well operator has an average monthly salary of $\$ 200$, so SWG automation will save a total of $\$ 3950$ for 10 tube wells as shown in Table 1. This assumes that the SCADA/IoT system will provide the following functionalities through automation thus making operators redundant

1. Pump Status (ON/OFF)

2. Remote Pump ON/OFF Control

3. Power Failure Alarm

4. Power Consumption Monitoring

5. Pump Running time and Scheduling

6. Historical Events \& Data Retrieval

Table 1 shows that installing an IoT based system with a backend cloud server is better from both the cost and complexity perspectives. Note that these cost savings are in addition to those due to the prevention of electricity and water theft. Electricity and water theft at tube well stations are a major financial burden on water utilities [9]. 
Table 1. Cost Comparison between Manual and SCADA/IoT Operation for 10 Tube Wells

\begin{tabular}{|l|l|l|}
\hline Description & $\begin{array}{l}\text { Manual Operation } \\
\text { Cost }\end{array}$ & SCADA/IoT Cost \\
\hline Operator 1 (Morning Shift) & $\$ 200 \times 10=\$ 2000$ & Not Required \\
\hline Operator 2 (Night Shift) & $\$ 200 \times 10=\$ 2000$ & Not Required \\
\hline Supervisor (One for 10 Tube Wells) & $\$ 300$ & $\$ 300$ \\
\hline Data Transmission/Month/Tube Well & $\mathrm{N} / \mathrm{A}$ & $\$ 5 \times 10=\$ 50$ \\
\hline Total & $\mathbf{\$ 4 3 0 0}$ & $\mathbf{\$ 3 5 0}$ \\
\hline
\end{tabular}

SWG system implementation has not been a priority in many countries due to cost concerns. Thus, the SWG system is evaluated here based on cost. There are two types of SWG systems [14], 1) field devices that interface with the existing SCADA systems of the utility providers, and 2) field devices (with or without a gateway) and a backend cloud server. In Pakistan, there are currently no SCADA or SWG systems for tube wells. Each tube well has a Motor Control Unit (MCU) which controls the submersible motors.

Table 2 gives the cost comparison between a SCADA system and the proposed SmartTubewell. This shows a significant difference in cost. For a developing country like Pakistan, a large cost per tubewell is a major impediment to the implementation of SWG systems. For the SCADA system, the largest cost is for licensing. Conversely, the cost for SmartTubewell is only $0.6 \%$ of that of a SCADA system. The internet data rate costs for SmartTubewell per month will not add significantly to the cost and will provide a stable and robust medium for communications.

Table 2. Per Tube Well Automation Costs for SCADA [15] and SmartTubewell

\begin{tabular}{|c|c|c|c|}
\hline \multicolumn{2}{|l|}{ SCADA System } & \multicolumn{2}{|l|}{ SmartTubewell } \\
\hline EQUIPMENT & COST & EQUIPMENT & COST \\
\hline Gateway & $\$ 380$ & $\begin{array}{l}\text { Current } \begin{array}{l}\text { Transformer } \\
\text { sensors (CT) }\end{array} \\
\end{array}$ & $\$ 33$ \\
\hline Agent Licensing & $\$ 1,130$ & Voltage Sensor & $\$ 42$ \\
\hline $\begin{array}{l}\text { Serial Module-Required for } \\
\text { each peripheral }\end{array}$ & $\begin{array}{l}\$ 316 \times 12=\$ \\
3,792\end{array}$ & MSU & $\$ 20$ \\
\hline Total/Site & $\$ 5,308$ & Raspberry Pi 3B & $\$ 35$ \\
\hline $\begin{array}{l}\text { Controller }+ \text { Unlimited } \\
\text { Agents Licensing }\end{array}$ & $\$ 16,274$ & 4G Cellular (GPRS) Module & $\$ 25$ \\
\hline Visual Module & $\$ 5,379$ & SD card (16 GB) & $\$ 30$ \\
\hline Reporting Module & $\$ 3,205$ & SEM unit & $\$ 18$ \\
\hline SQL Bridge Module & $\$ 1,356$ & Battery (12V $7000 \mathrm{mAh})$ & $\$ 10$ \\
\hline SFC Module & $\$ 3,164$ & Battery Charger & $\$ 14$ \\
\hline Alarm Notification Module & $\$ 1,536$ & & \\
\hline Tag Historian & $\$ 1,627$ & & \\
\hline Total Cost & $\$ 43,947.2$ & Total Cost & $\$ 227$ \\
\hline
\end{tabular}




\section{ORIGINALITY}

In this work, an IoT based solution SmartTubewell is proposed for developing a reliable and efficient SWG system. This overcomes the limitations of current WDNs of developing countries. These limitations include water waste/loss/overuse, NRW, energy theft and underground water table management. SmartTubewell is low cost, reliable and scalable solution for automating a tube well station. It has a lower cost than both manual and SCADA based tubewell automation systems. In fact, the SmartTubewell cost is only $0.6 \%$ of that of a SCADA based system. This solution can incentivize developing countries to upgrade their WDNs as until now cost was a major concern of local municipalities and utilities.

SmartTubewell is composed of sensor nodes based on a Raspberry Pi with integrated current and voltage sensors. These nodes are integrated with the three-phase submersible water motors installed at each tube well station. They are used for real-time monitoring, automation and control of tube wells with a local database for logging purposes. An AWS based application layer and back-end database are employed for control, scheduling, monitoring and management of the tube well stations. Data from the sensor nodes is transmitted to the AWS servers using cellular (GPRS) communication. This data can be analyzed to determine the energy efficiency of each tube well station as well as the amount of water extracted to identify energy theft, schedule maintenance and reduce costs.

\section{SYSTEM DESIGN}

The SmartTubewell system IoT architecture has three layers as shown in Figure 4. From bottom to top, these are the perception, transport and application layers. These layers are explained below.

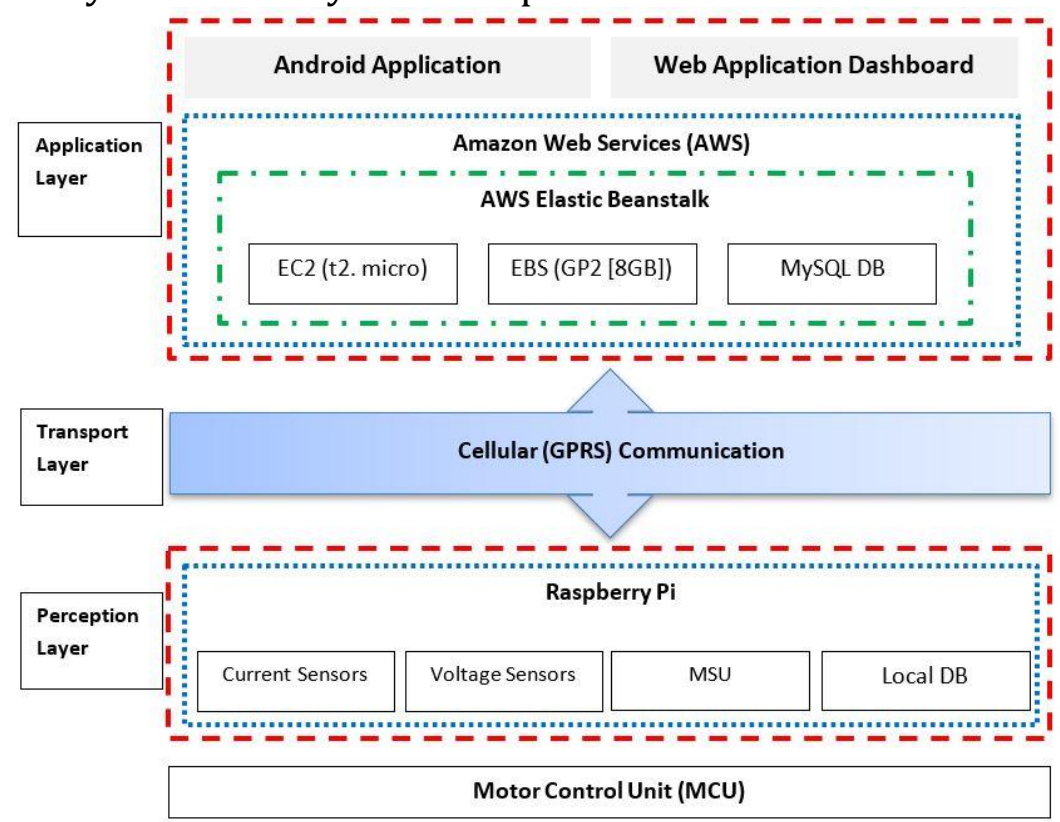

Figure 4. The SmartTubewell system architecture. 


\subsection{Perception Layer}

The perception layer contains the sensor nodes consisting of sensors and actuators. They are integrated with the submersible water pumps at the tube well stations as shown in Figure 5. The sensor nodes obtain real-time data about the physical state of the submersible motor, water flow and electricity consumption. They are instrumental in controlling, scheduling and maintaining the tube wells.

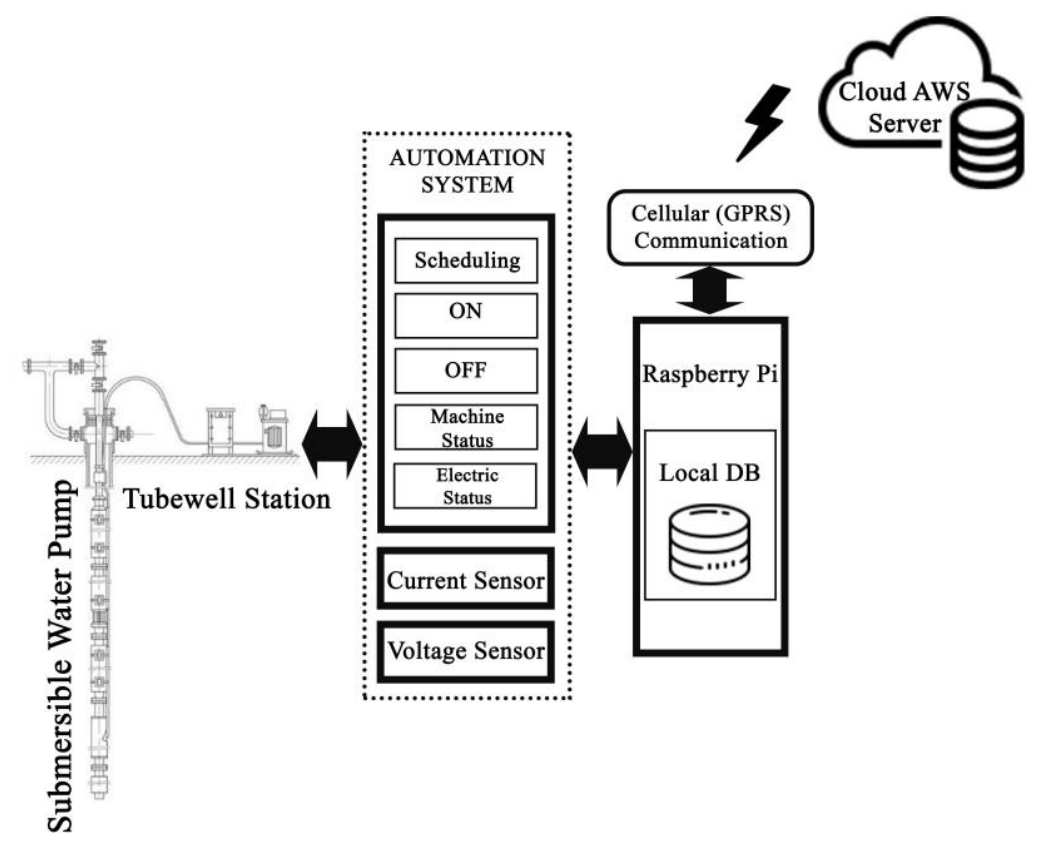

Figure 5. SmartTubewell block diagram.

The sensor node is based on a Raspberry Pi (RPi) model 3B [16]. It is a popular single board computer with many applications because of the builtin Wi-Fi adaptor and 40 pin GPIO header. Raspbian Jessie based on Debian Linux is used as the operating system. The software for tube well automation and real-time data acquisition is written in Python. Current and voltage sensors are employed with the RPi to measure tube well electricity consumption. In particular, a Hall Effect non-intrusive Current Transformer (CT) is used to measure electricity loads up to $100 \mathrm{~A}$. An AC-to-AC voltage adaptor is used which consists of a step-down transformer with a $240 \mathrm{~V} \mathrm{AC}$ input and a $9 \mathrm{~V} \mathrm{AC}$ output. The sensed current and voltage parameters are sent to the RPi after analog to digital conversion.

A local database is maintained on the RPi which logs tube well physical state data. This database is identical to the cloud database except that it contains only local data. The databases are synchronized every minute. In case of internet connection disruption, data is stored locally until the connection is restored. 


\subsection{Transport Layer}

The choice of a communications technology should consider parameters such as range, spectrum, scalability and data transmission costs [14]. For SmartTubewell, cellular (GPRS) communications are employed as it is stable, secure, and reliable. Using a cellular network also reduces the cost of communications as shown in Table 2. For SWG systems where tube well stations are far apart, Very High Frequency (VHF) or Ultra High Frequency (UHF) based communication solutions are not suitable. They require gateways and repeaters for long-range communications which will significantly increase the cost. Cellular data rates are very competitive in Pakistan, so the cost of cellular communications is low compared to other technologies. SmartTubewell synchronizes the data from a tube well station every minute by sending 514 bytes, so the amount of data sent per month is only 22.2 MB. In Pakistan, $6000 \mathrm{MB}$ of data costs just $\$ 5$ per month.

\subsection{Application Layer}

The application layer is designed to efficiently control and monitor the real-time operation of each tube well station. It is a user-oriented layer that processes and displays the data. It provides a centralized command and control center where all stations in the metropolitan area can be monitored and controlled. It can be divided into three modules as detailed below.

\subsubsection{Cloud Platform}

The AWS cloud platform [17] is used to provide data accessibility and a centralized communication server for the perception and application layers. Elastic Beanstalk is one of many services available on the AWS platform. It can be used to deploy and manage an application in the cloud without knowledge of the infrastructure. Elastic Beanstalk automatically allocates resources for load balancing, scaling, capacity allocation and application health monitoring. It supports applications developed in many programming languages such as Python, Node.Js, and PHP. For the proposed system, AWS Elastic Beanstalk is used to run the web application with PHP 7.2 running on 64-bit Amazon Linux/2.8.14. A t2.micro EC2 instance is run with elastic block store volume type gp2 having an initial capacity of 8 GB. The HTTP protocol is used for data communication with the sensor nodes via APIs.

\subsubsection{Web Application}

A web application with a Graphical User Interface (GUI) is employed to monitor and control each tube well station. The dashboard is shown in Figure 6. This gives the geographic location and operational status of all automated tubewell stations. It also enables the user to add or delete tubewell stations. Figure 7 shows the list page which presents all the tube well stations with the corresponding information. This information includes electricity consumption, electricity billing, current operational status, and 
operational log tables. These log tables have detailed information regarding on/off times such as scheduled changes. The operator identity is also provided as a deterrent to water and electricity theft.

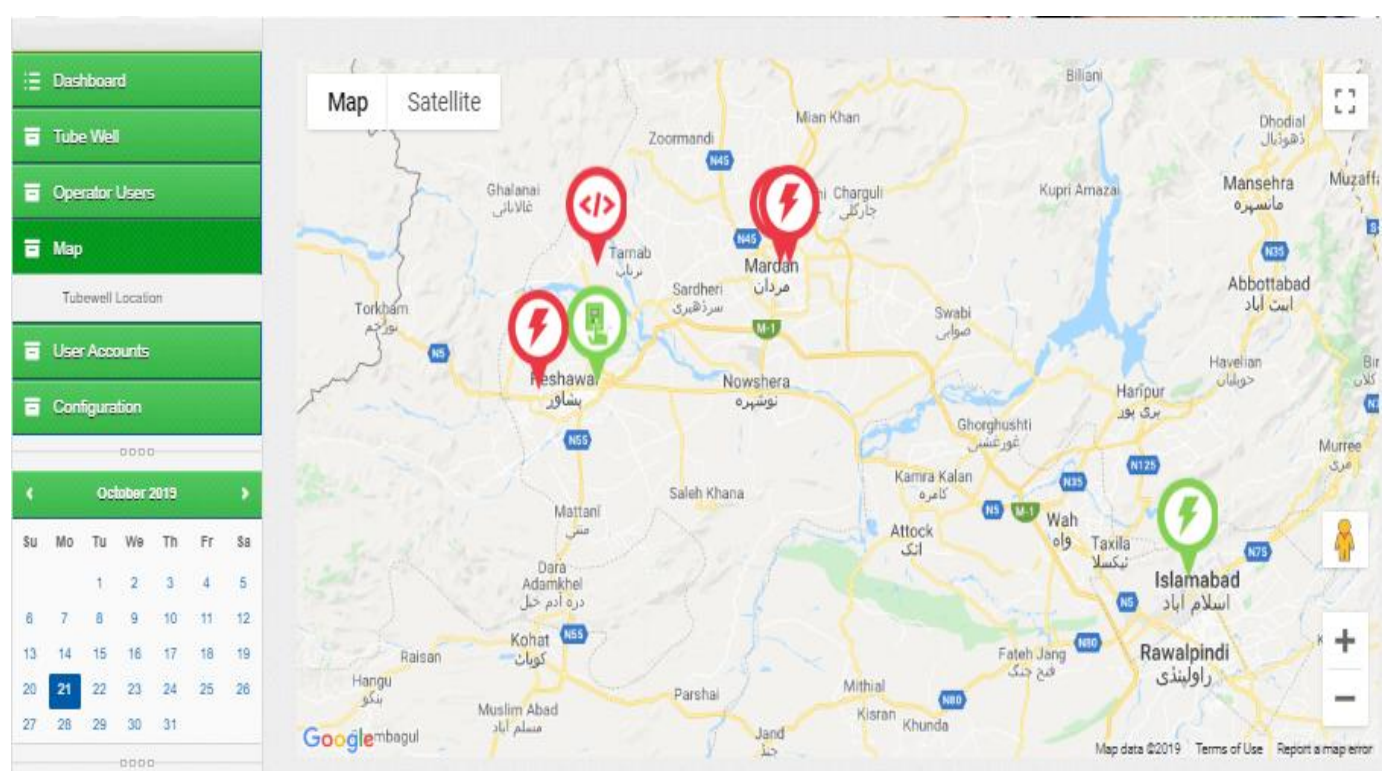

Figure 6. The web dashboard.

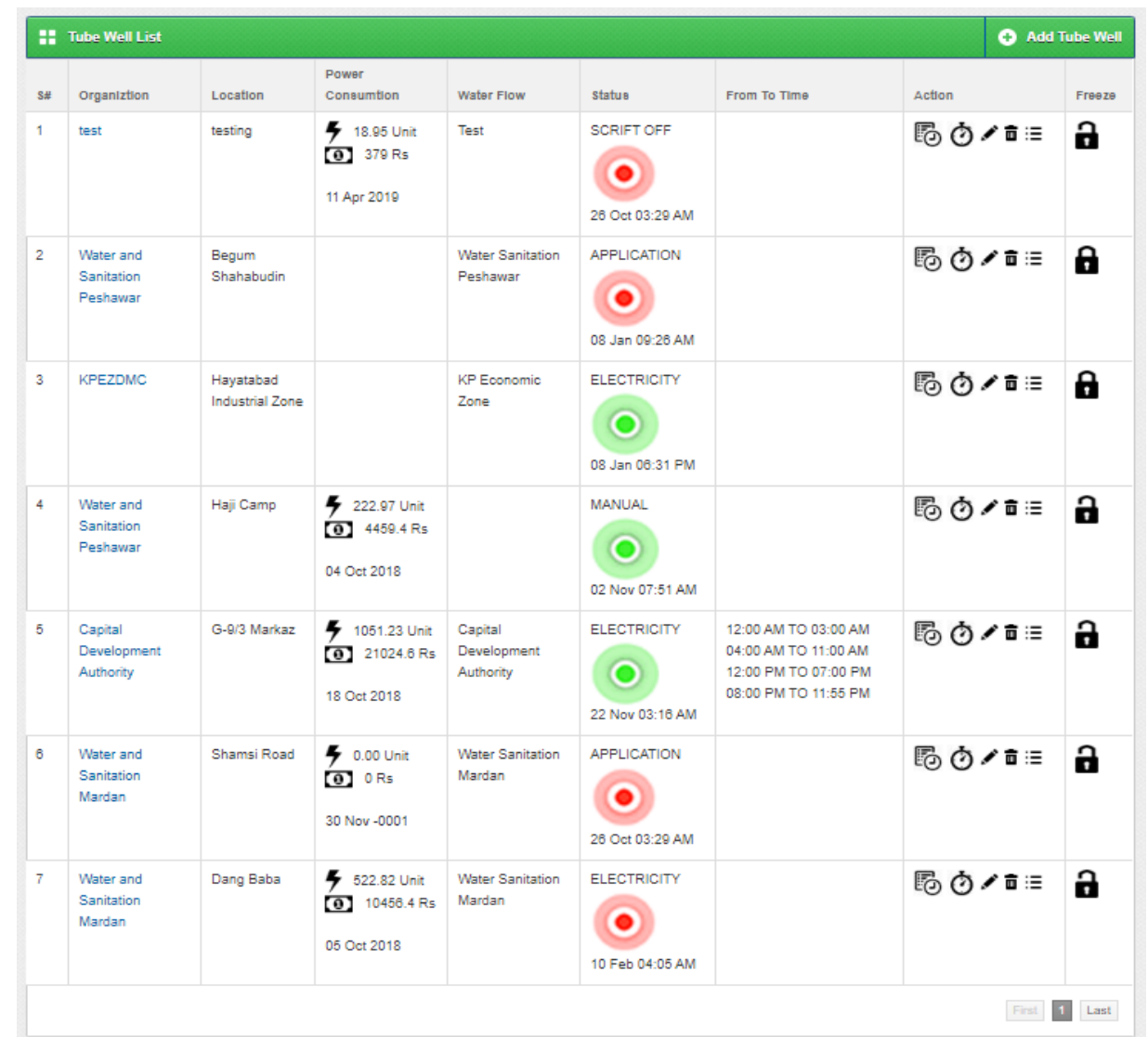

Figure 7. The list page which provides information for individual tube wells. 


\subsubsection{Android Application}

An Android application was developed for SmartTubewell to enable authorities to remotely control and monitor their tube well stations. The status of the stations can be monitored as shown in Figure 8. This app provides information such as operating status of individual stations (blue icon for on and red for off), operator identity (who turned the station on or off), change type (manual, scheduled or due to a loss of power), and operational log data (such as water outflow and electricity consumption). SmartTubewell enables water utilities to monitor their tube well stations via operational logs. These logs contain the start/stop time and the type of change (manual, scheduled, using the app or loss of power) as shown in Figures 7 and 8(c). To reduce water and electricity theft, usernames and passwords can be assigned to authorized personnel. SmartTubewell can log information on each authorized person. Access to the mobile application is via two-factor authentication which includes the IMEI number of the smartphone. In an emergency, manual operation of the stations can be allowed. In this case, the operational logs should be monitored to detect any suspicious activities.

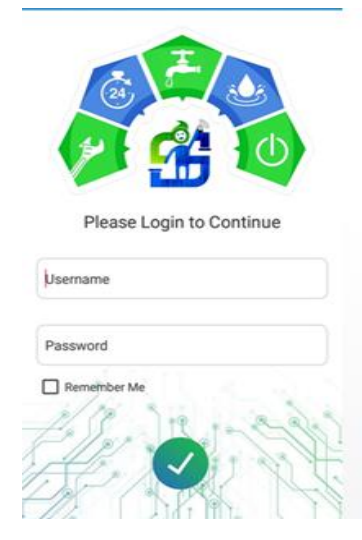

(a)

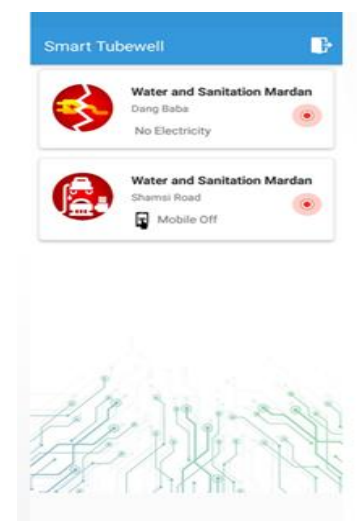

(b)

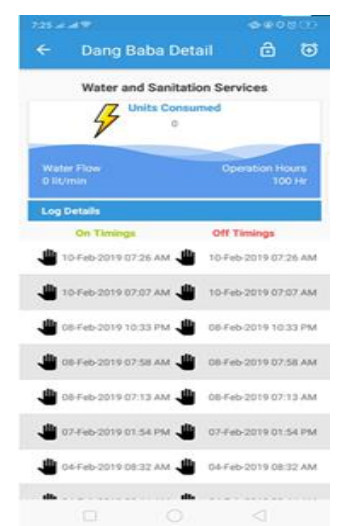

(c)

Figure 8. Android application layout (a) user login view, (b) tube well list view, and (c) detailed information view.

\section{EXPERIMENTAL RESULTS AND ANALYSIS}

In the pilot phase, SmartTubewell was deployed by the WSSP, PDA and Islamabad water utilities. In this section, field results are given for a tube well station in the Hayatabad Township which is shown in Figure 3. This tube well is managed by the Khyber Pakhtunkhwa Economic Zone Management and Development (KPEZMD) Company. KPEZMD is a utility provider to the Hayatabad Township industrial zone. Constant monitoring and data analytics are essential for SWG system implementation. SmartTubewell was installed at the tube well station to automate a $40 \mathrm{HP}$ water pump. This station was 
operated remotely and autonomously for 31 days from October 1,2019 , to October 31, 2019. An inspector was located at the station to check the accuracy and reliability of the system. Thus, data related to the operation and electricity consumption of the tube well was monitored both manually and autonomously. The results obtained show that the proposed solution has high accuracy and reliability.

The operation of the tube well station depends on the availability of electricity. As is normally the case in developing countries, electricity blackouts are common in Pakistan, especially in summers. Therefore, tube wells are operated throughout the day at different times according to when electricity is available. Thus, the operating time per day will vary as shown in Figure 9. This indicates that on October 23, the tube well was in operation for only 3.2 hours. Politics also affect operating times as officials pressure utilities to operate tube well stations according to their agendas. With SmartTubewell, utilities will be able to accurately monitor operating hours and take appropriate actions. The electricity consumption of the KPEZMD tube well station for October 2019 was $8174.6 \mathrm{kWh}$ according to the SmartTubewell system. The consumption according to the electricity provider differed by only $3 \%$.

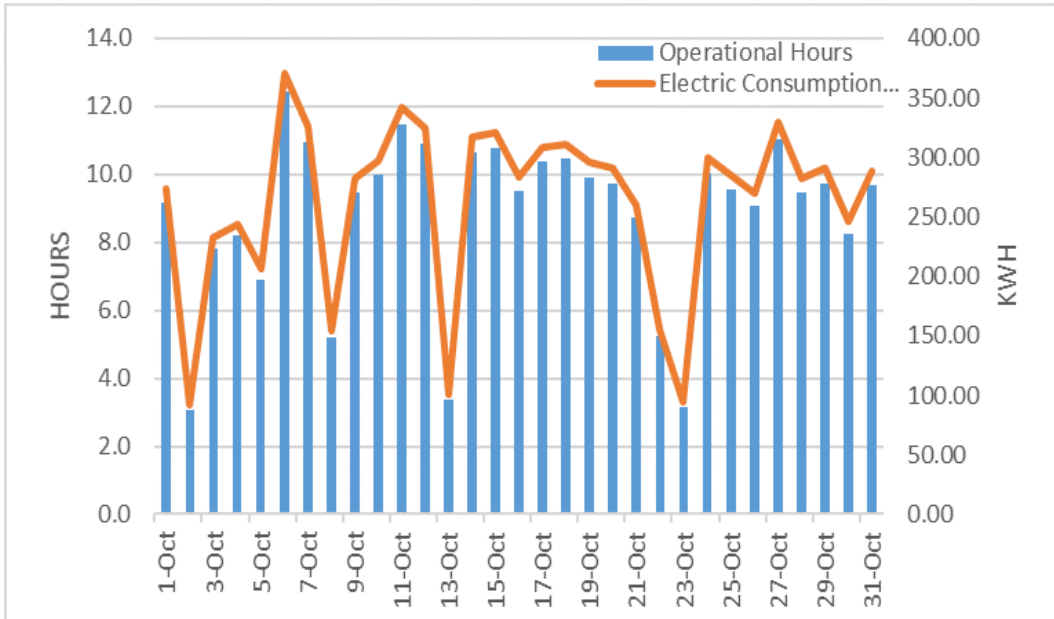

Figure 9. The number of operational hours versus electricity consumption the KPEZMD station for a period of 31 days.

In addition to mitigating water and electricity theft, SmartTubewell can be used to detect inefficiencies in tube well operations. Parameters that affect efficiency include groundwater level, depth of the submersible water pump and pipe friction. In addition, old tube wells consume more energy per cubic meter of water extracted than new ones. More than $50 \%$ of the tube well stations in Peshawar are over 15 years old [9]. The efficiency can be evaluated by analyzing electricity consumption versus water flow as shown in Figure 10. 


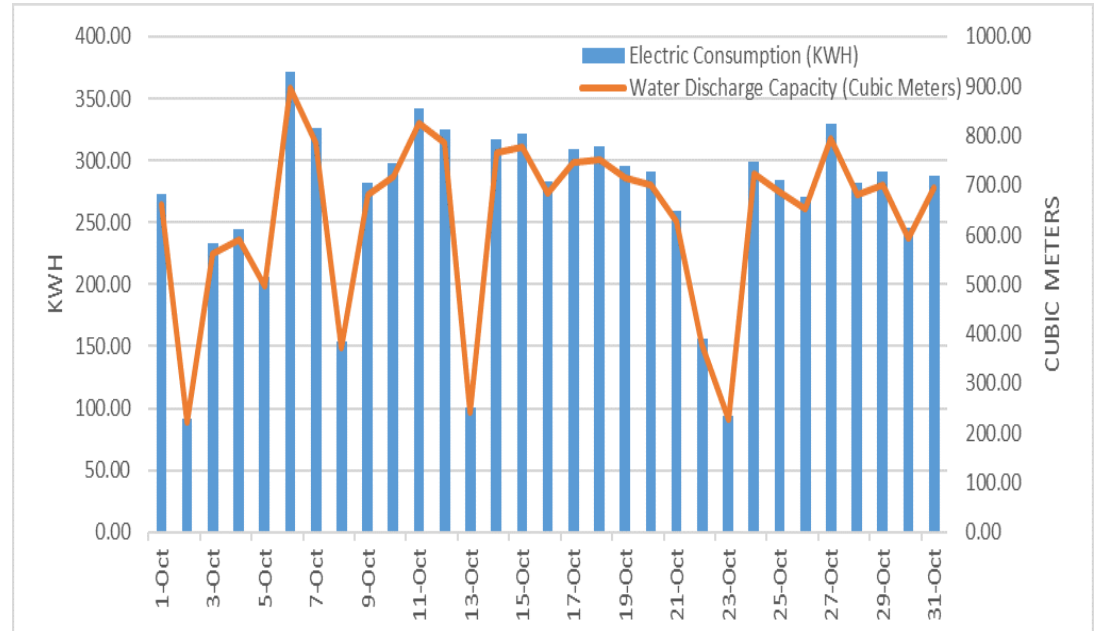

Figure 10. Electricity consumption versus water flow at the KPEZMD station for a period of 31 days.

A water flow meter was also installed on the main pipe of the water motor. The water discharged at the tube well station is shown in Figure 10. In Pakistan, electricity is provided to tube well stations at a flat rate of $\$ 0.13 / \mathrm{kWh}$. The amount of electricity consumed per cubic meter of water was $2.4 \mathrm{kWh}$ so the cost is $\$ 0.312 /$ cubic meter. The data obtained from SmartTubewell is essential for effective water supply management. Further, automated scheduling is a key component of the proposed system.

\section{CONCLUSION}

A low cost, reliable and scalable IoT based solution for SWG called SmartTubewell was presented. The objective was to improve the performance of obsolete water management systems to overcome water management issues such as water loss/waste, NRW and groundwater depletion levels. A SmartTubewell sensor node can be deployed to automate a tubewell station at a cost of $\$ 277$. This cost can be recouped within a month due to tube well automation which makes two human operators redundant. The cost of SmartTubewell is only $0.6 \%$ of the corresponding SCADA system. The most important advantage of SmartTubewell is scalability as the cost of $\$ 277$ per tube well station is sufficiently low that thousands of stations can automated at a reasonable cost.

SmartTubewell was field tested by automating a KPEZMD tube well station for 31 days. During this period, SmartTubewell controlled station operation and logged the data including operating hours and time, electricity consumed, water pumped and cost per cubic meter of water. The application layer employs the AWS cloud computing platform to provide scalability, elasticity, and reliability for the required computing resources. 
The architecture of this system was presented and compared with a SCADA based system based on features, capital investment and operational cost. This showed that the proposed system is a better choice for developing countries such as Pakistan. SmartTubewell can be used to reduce the operational costs of water distribution by identifying redundancies and losses. SmartTubewell provides real-time remote monitoring and control of tube well stations via an Android application and a centralized cloud-based web dashboard. If implemented over a large region (such as Peshawar), this system can help utilities improve water distribution efficiency and sustainability by reducing water loss $\backslash$ waste $\backslash$ leakage, NRW and electricity theft.

\section{ACKNOWLEDGEMENTS}

This project was supported by the Higher Education Commission, Pakistan, under the establishment of the National Centre of Big Data and Cloud Computing at UET Peshawar.

\section{REFERENCES}

[1] Safdar, Sabeeh, Mujahid Mohsin, Liaqat Ali Khan, and Waseem Iqbal. Leveraging the internet of things for smart waters: Motivation, enabling technologies and deployment strategies for Pakistan. In IEEE SmartWorld, Ubiquitous Intelligence \& Computing, Advanced \& Trusted Computing, Scalable Computing \& Communications, Cloud \& Big Data Computing, Internet of People and Smart City Innovation, pp. $2117-$ 2124. 2018.

[2] Mahessar, A. A., A. L. Qureshi, N. A. Memon, S. Qureshi, and I. A. Bohio. "Impact assessment of effluent from Kotri industrial site area on environment. Science International (Lahore) 28, no. 4 (2016): 35353540.

[3] Bellavista, Paolo, Giuseppe Cardone, Antonio Corradi, and Luca Foschini. Convergence of MANET and WSN in IoT urban scenarios. IEEE Sensors Journal 13, no. 10 (2013): 3558-3567.

[4] Hussain, Sayed Shahid, Khurram S. Khattak, Ali Khan, and Zawar H. Khan. Cyber physical system for solar energy monitoring. In IEEE International Conference on Frontiers of Information Technology, pp. 185-1855. 2019.

[5] Khan, Nauman, Khurram S. Khattak, Shaukat Ullah, and Zawar Khan, A low-cost IoT based system for environmental monitoring. In IEEE International Conference on Frontiers of Information Technology, pp. 173-1735. 2019.

[6] Malik, Haroon, Khurram S. Khattak, Tousiq Wiqar, Zawar H. Khan, and Ahmed B. Altamimi. "Low cost internet of things platform for structural health monitoring. In IEEE International Multitopic Conference. 2019. 
[7] Sohail, Anwar Mehmood, Khurram S. Khattak, Adil Iqbal, Zawar H. Khan, and Aakash Ahmad. Cloud-based detection of road bottlenecks using OBD-II telematics, IEEE International Multitopic Conference, 2019.

[8] UNESCO, Leaving no one behind, The United Nations World Water Development Report, 2019.

[9] Urban Policy Unit Khyber Pakhtunkhwa, Planning and engineering services for master plan in Peshawar Khyber Pakhtunkhwa drinking water, sanitation/storm water and solid waste services, 2020.

[10] Khan, Attaullah, and Muhammad Ali, Impact of built environment on groundwater depletion in Peshawar, Pakistan, Journal of Himalayan Earth Sciences 52, no. 1 (2019): 86.

[11] Ministry of Water Resources Government of Pakistan, National water policy. 2018.

[12] Gupta, Aditya, Sudhir Mishra, Neeraj Bokde, and Kishore Kulat, Need of smart water systems in India, International Journal of Applied Engineering Research 11, no. 4 (2016): 2216-2223.

[13] Mutchek, Michele, and Eric Williams, Moving towards sustainable and resilient smart water grids, Challenges 5, no. 1 (2014): 123-137.

[14] Kulkarni, Parag, and Tim Farnham, Smart city wireless connectivity considerations and cost analysis: Lessons learnt from smart water case studies, IEEE Access 4 (2016): 660-672.

[15] Inductive Automation, Ignition: The new SCADA, Date: 2020, January 3, 2018 [Online] Available: https://inductiveautomation.com/scadasoftware/.

[16] Raspberry Pi Foundation, Raspberry Pi 3B, Date: 2020, January, 3 [Online] Available: https://www.raspberrypi.org/.

[17] Amazon, Amazon web services, Date: 2020 January 18; [Online] Available: https://aws.amazon.com/. 